\title{
Alterations in Sulfur Amino Acid Metabolism in Mice Treated with Silymarin: A Novel Mechanism of Its Action Involved in Enhancement of the Antioxidant Defense in Liver
}

Authors

Affiliations
Do Young Kwon ${ }^{1}$, Young Suk Jung ${ }^{1}$, Sun Ju Kim ${ }^{1}$, Young Soon Kim² ${ }^{2}$ Dal Woong Choi ${ }^{3}$, Young Chul Kim ${ }^{1,4}$

${ }^{1}$ College of Pharmacy, Seoul National University, Seoul, Korea

${ }^{2}$ Department of Food \& Nutrition, College of Health Sciences, Korea University, Seoul, Korea

${ }^{3}$ Department of Environmental Health, College of Health Sciences, Korea University, Seoul, Korea

${ }^{4}$ Research Institute of Pharmaceutical Sciences, Seoul National University, Seoul, Korea
Key words

- Silybum marianum

- Asteraceae

- silymarin

- glutathione

- sulfur amino acid metabolism

- antioxidant received March 14, 2013

revised May 20, 2013

accepted May 24, 2013

Bibliography

Dol http://dx.doi.org/

10.1055/s-0032-1328704

Published online June 27, 2013

Planta Med 2013; 79: 997-1002

(c) Georg Thieme Verlag KG

Stuttgart · New York .

ISSN 0032-0943

Correspondence

Dr. Young C. Kim

College of Pharmacy

Seoul National University

San 56-1 Shinrim-Dong

Kwanak-Ku, Seoul 151-742

Korea

Phone: +8228807852

Fax: +8228717453

youckim@snu.ac.kr

\section{Abstract \\ $\nabla$}

It has been known that silymarin exhibits protective activity against oxidative liver injury induced by various hepatotoxicants, but the underlying mechanism of its beneficial action remains unclear. We determined the alterations in sulfurcontaining amino acid metabolism induced by silymarin in association with its effects on the antioxidant capacity of liver. Male mice were treated with silymarin (100 or $200 \mathrm{mg} / \mathrm{kg}$, p.o.) every $12 \mathrm{~h}$ for a total of 3 doses, and sacrificed $6 \mathrm{~h}$ after the final dosing. The hepatic methionine level was increased, but the activity and protein expression of methionine adenosyltransferase were decreased by silymarin in a dose-dependent manner. S-Adenosylmethionine or homocysteine concentration was not changed, whereas the sulfurcontaining metabolites generated from homocysteine in the transsulfuration pathway including cystathionine, cysteine, and glutathione were increased significantly. Cystathionine $\beta$-synthase was induced, but cysteine dioxygenase was downregulated, both of which would contribute to the elevation of cysteine and its product, glutathione, in liver. Oxygen radical scavenging capacity of liver cytosol against peroxyl radical and peroxynitrite was increased, and also hepatic lipid peroxidation was diminished in the silymarin-

\section{Introduction}

$\nabla$

Silymarin, a mixture of four flavonolignan isomers (silybin, isosilybin, silydianin, silychristin), extracted from the seed of milk thistle (Silybum marianum; Asteraceae) has been used for the treatment of liver injury in traditional medicine. Numerous studies have shown that silymarin protects liver cells from various hepatotoxicants such as ethanol, diethylnitrosamine, and carbon tetrachloride [1-3]. Generation of oxidative stress treated mice. Taken together, the results demonstrate that silymarin enhances hepatic glutathione generation by elevating cysteine availability via an increment in cysteine synthesis and an inhibition of its catabolism to taurine, which may subsequently contribute to the antioxidant defense of liver.

\begin{tabular}{|c|c|}
\hline BHMT: & $\begin{array}{l}\text { betaine-homocysteine methyltrans- } \\
\text { ferase }\end{array}$ \\
\hline $\mathrm{C} \beta \mathrm{S}:$ & cystathionine $\beta$-synthase \\
\hline CDC: & cysteine sulfinate decarboxylase \\
\hline CDO: & cysteine dioxygenase \\
\hline CYL: & cystathionine $\gamma$-lyase \\
\hline GCS: & $\gamma$-glutamylcysteine synthetase \\
\hline GSH: & glutathione \\
\hline GSSG: & oxidized form of GSH \\
\hline KMBA: & $\alpha$-keto- $\gamma$-methiolbutyric acid \\
\hline MAT: & methionine adenosyltransferase \\
\hline MS: & methionine synthase \\
\hline SAH: & S-adenosylhomocysteine \\
\hline SAM: & $S$-adenosylmethionine \\
\hline TBARS: & thiobarbituric acid reactive substance \\
\hline TOSC: & total oxyradical scavenging capacity \\
\hline
\end{tabular}




\begin{tabular}{|c|c|c|c|}
\hline & Control & Silymarin (100 mg/kg) & Silymarin $(200 \mathrm{mg} / \mathrm{kg})$ \\
\hline Methionine (nmol/g liver) & $38.2 \pm 1.4^{\mathrm{a}}$ & $46.7 \pm 2.5^{\mathrm{a}, \mathrm{b}}$ & $51.1 \pm 6.2^{b}$ \\
\hline SAM (nmol/g liver) & $99.3 \pm 5.2$ & $95.5 \pm 4.4$ & $108.8 \pm 8.6$ \\
\hline SAH (nmol/g liver) & $46.0 \pm 2.4$ & $49.1 \pm 4.4$ & $53.1 \pm 4.6$ \\
\hline Homocysteine (nmol/g liver) & $6.8 \pm 0.5$ & $6.8 \pm 0.2$ & $6.4 \pm 0.3$ \\
\hline Cystathionine ( $\mathrm{nmol} / \mathrm{g}$ liver) & $9.9 \pm 1.4^{\mathrm{a}}$ & $13.5 \pm 1.6^{\mathrm{a}, \mathrm{b}}$ & $16.7 \pm 1.2^{b}$ \\
\hline Cysteine (nmol/g liver) & $89.3 \pm 9.3^{a}$ & $84.4 \pm 3.2^{\mathrm{a}}$ & $149.1 \pm 10.3^{b}$ \\
\hline Hypotaurine ( $\mu \mathrm{mol} / \mathrm{g}$ liver) & $0.13 \pm 0.02$ & $0.14 \pm 0.03$ & $0.16 \pm 0.02$ \\
\hline Taurine ( $\mu \mathrm{mol} / \mathrm{g}$ liver) & $13.0 \pm 0.7$ & $13.4 \pm 0.7$ & $14.7 \pm 0.4$ \\
\hline GSH ( $\mu \mathrm{mol} / \mathrm{g}$ liver) & $5.7 \pm 0.3^{a}$ & $5.9 \pm 0.3^{a}$ & $6.9 \pm 0.2^{b}$ \\
\hline GSSG ( $\mu \mathrm{mol} / \mathrm{g}$ liver) & $0.22 \pm 0.01$ & $0.20 \pm 0.01$ & $0.22 \pm 0.01$ \\
\hline GSH/GSSG & $25.4 \pm 0.6^{\mathrm{a}}$ & $29.9 \pm 0.9^{b}$ & $31.7 \pm 1.2^{b}$ \\
\hline
\end{tabular}

Each value is the mean \pm SE for 5 mice. Values with different letters (a, b) are significantly different from one another (one-way ANOVA followed by Newman-Keuls multiple range test, $\mathrm{p}<0.05$ )

\begin{tabular}{|lccc|}
\hline & Control & Silymarin (100 $\mathbf{~ m g / k g )}$ & Silymarin (200 $\mathbf{~ m g / k g ) ~}$ \\
\hline MAT (pmol/min/mg protein) & $41.3 \pm 3.2^{\mathrm{a}}$ & $38.5 \pm 1.4^{\mathrm{a}, \mathrm{b}}$ & $32.5 \pm 1.8^{\mathrm{b}}$ \\
\hline BHMT (nmol/min/mg protein) & $1.55 \pm 0.14^{\mathrm{a}}$ & $1.34 \pm 0.10^{\mathrm{a}, \mathrm{b}}$ & $1.14 \pm 0.10^{\mathrm{b}}$ \\
\hline C $\beta S$ (nmol/min/mg protein) & $7.1 \pm 0.6^{\mathrm{a}}$ & $8.7 \pm 0.8^{\mathrm{a}, \mathrm{b}}$ & $10.1 \pm 0.8^{\mathrm{b}}$ \\
\hline C $\mathrm{L}$ (nmol/min/mg protein) & $10.1 \pm 0.1$ & $10.4 \pm 0.4$ & $10.7 \pm 0.5$ \\
\hline CDO (nmol/min/mg protein) & $0.62 \pm 0.07^{\mathrm{a}}$ & $0.40 \pm 0.02^{\mathrm{b}}$ & $0.32 \pm 0.02^{\mathrm{b}}$ \\
\hline CDC (nmol/min/mg protein) & $16.3 \pm 0.8$ & $16.1 \pm 1.3$ & $17.3 \pm 1.1$ \\
\hline CCS (nmol/min/mg protein) & $3.8 \pm 0.4$ & $3.3 \pm 0.1$ & $3.2 \pm 0.5$ \\
\hline
\end{tabular}

Table 2 Effect of silymarin on the enzyme activities involved in sulfur amino acid metabolism.

Each value is the mean \pm SE for 5 mice. Values with different letters (a, b) are significantly different from one another (one-way ANOVA followed by Newman-Keuls multiple range test, $p<0.05$ )

jor constituent of silymarin, can directly scavenge hydroxyl radicals (HO) [5] and hypochlorous acids ( $\mathrm{HOCl}$ ) [6]. Also, silybinphosphatidyl choline complex was demonstrated to scavenge hydroxyethyl radicals in hepatic microsomes and bile of ethanol-fed rats [7].

Previous studies have shown that in experimental animals challenged with a hepatotoxic substance, silymarin administration attenuates the toxicant-induced GSH depletion [1-3]. This is usually considered to be a secondary effect, resulting from the preservation of GSH in the antioxidant defense against hepatotoxicants owing to the direct radical scavenging activity of silymarin. However, an increase in hepatic GSH content was noted in rodents treated with silymarin only in a few studies conducted by others $[8,9]$, and also in our laboratory (unpublished observation), suggesting that this substance might be capable of directly influencing the GSH concentration in liver. Therefore, it was of interest to examine the effects of silymarin on hepatic metabolism of sulfur-containing amino acids in association with the antioxidant capacity of liver using an animal model.

\section{Results}

$\nabla$

The hepatic methionine level was increased by silymarin treatment, but its metabolites in the methionine cycle, SAM, SAH, and homocysteine, were not influenced ( Table 1). Silymarin treatment elevated the transsulfuration products from homocysteine, such as cystathionine, cysteine, and GSH, significantly. The GSH/GSSG ratio was also elevated, which might be due to the increase in de novo synthesis of GSH in liver. On the other hand, the other major metabolites of cysteine, hypotaurine and taurine, were not changed in the liver of the silymarin-treated mice.
BHMT and MAT activities in liver were decreased by silymarin in a dose-dependent manner ( $\odot$ Table 2 ). But C $\beta$ S activity was increased significantly. The activity of CDO was inhibited markedly, while GCS was not altered by silymarin treatment. The alteration in the enzyme activities appeared to be directly related to the protein expressions because the tendency of the changes in activities was mostly equal to that of proteins ( Fig. 1). BHMT and MAT I/III were decreased, whereas $\mathrm{C} \beta \mathrm{S}$ was increased by silymarin treatment. CDO expression in the liver of the mice treated with silymarin was also lower than that found in the control animals. The hepatic level of TBARS was reduced by silymarin treatment significantly ( Fig. 2). The specific TOSC of liver cytosol toward hydroxyl radicals and peroxynitrite was increased dose-dependently in the silymarin-treated mice ( Fig. 3). Also, the cytosolic fraction of the liver from the silymarin-treated mice appeared to scavenge hydroxyl radicals more effectively than that of the control liver, although no statistical significance was noted. Therefore, the reduction of TBARS and the elevation of TOSC were nearly parallel to the increase in GSH and GSH/GSSG caused by silymarin treatment.

\section{Discussion}

In this study, we examined the changes in hepatic sulfur-containing amino acid metabolism in the mice treated with silymarin acutely. The results show that silymarin alters the metabolism of sulfur amino acids extensively in normal mouse liver not exposed to extra oxidants. Particularly, silymarin increases the hepatic level of cysteine which is the essential substrate for GSH synthesis. It is thus suggested that the antioxidant activity of silymarin may be, at least in part, attributed to the increase in cysteine 


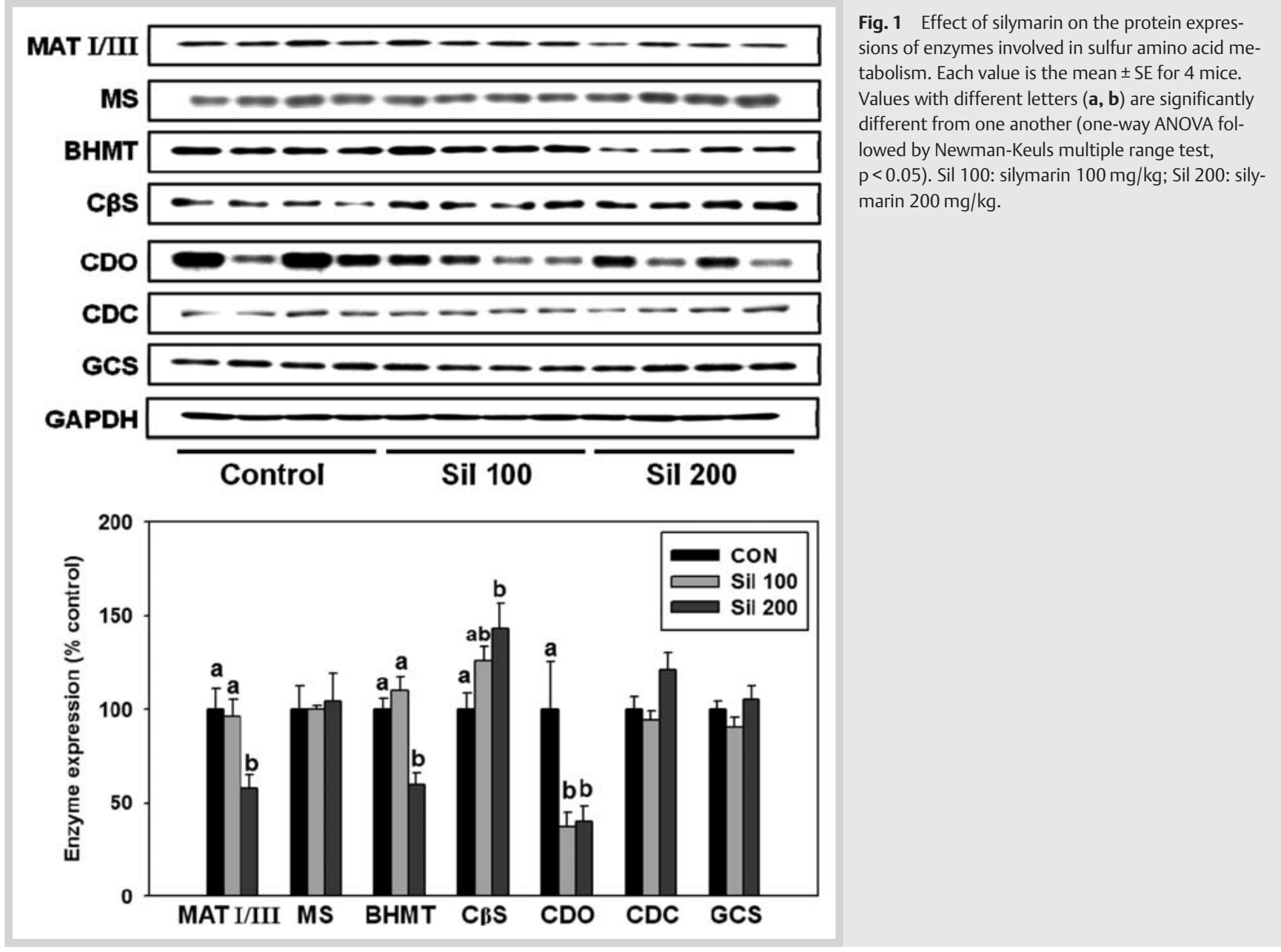

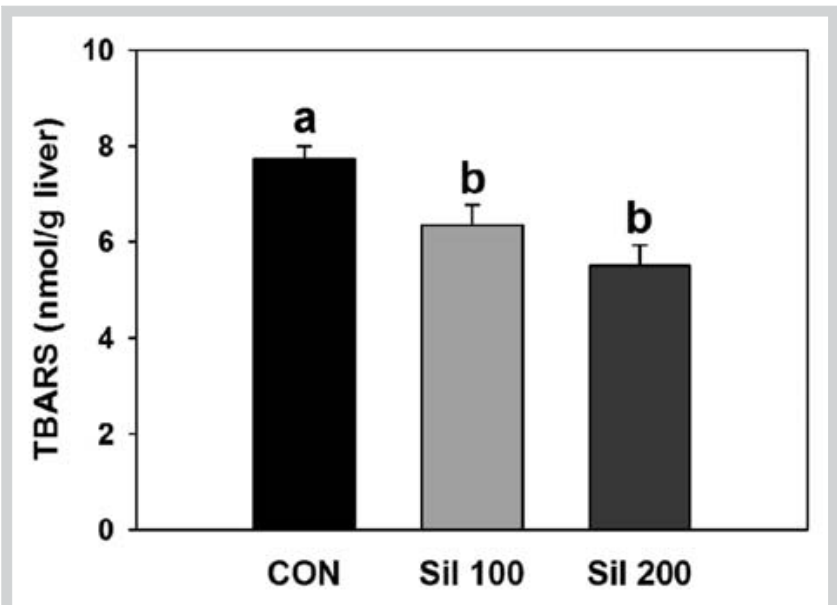

Fig. 2 Effect of silymarin on hepatic lipid peroxidation. Each value is the mean \pm SE for 5 mice. Values with different letters $(\mathbf{a}, \mathbf{b})$ are significantly different from one another (one-way ANOVA followed by Newman-Keuls multiple range test, $\mathrm{p}<0.05$ ).

availability, which results in an enhancement of GSH generation in liver.

In the first step of hepatic metabolism of sulfur amino acids, methionine sulfur is transferred to SAM by the activity of MAT. MAT

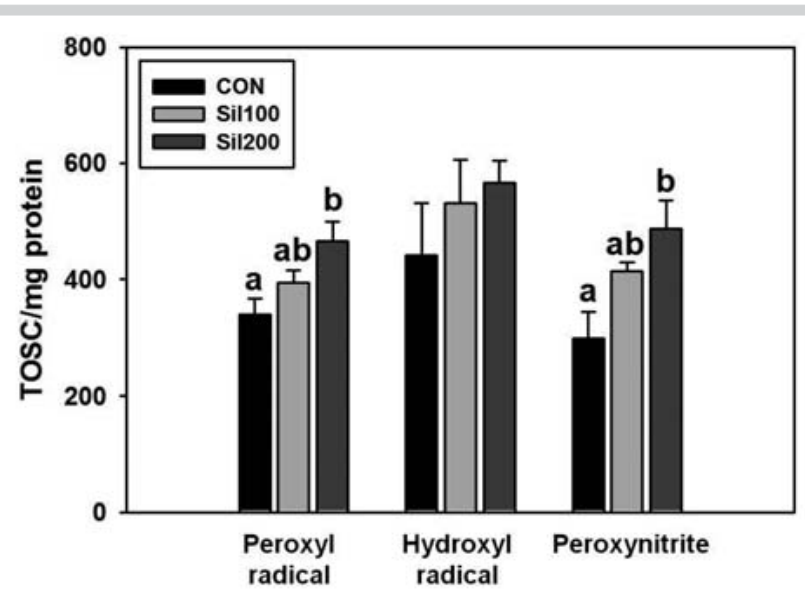

Fig. 3 TOSC of liver cytosol from the mice treated with silymarin. Each value is the mean $\pm \mathrm{SE}$ for 5 mice. Values with different letters $(\mathbf{a}, \mathbf{b})$ are significantly different from one another (one-way ANOVA followed by Newman-Keuls multiple range test, $p<0.05$ ).
I and MAT III are liver-specific forms, and MAT II is an extrahepatic form. In this study, silymarin decreased MAT activity and MAT I/III protein expression, which may be responsible for the accumulation of methionine in liver. Regulation of MAT I/III pro- 
tein expression is largely unknown, although our previous work shows that this enzyme is subject to post-translational regulation by oxidative stress [10]. SAM is demethylated to SAH, and SAH is further hydrolyzed to produce homocysteine, which is either remethylated to methionine or condensed with serine to yield cystathionine. The remethylation of homocysteine is catalyzed by BHMT and MS. In this study, the expression of MS was not changed, but BHMT was downregulated by silymarin ( $\bullet$ Fig. 1, Table 2), which could be due to the accumulation of methionine in liver. The reduction of BHMT activity would decrease the remethylation of homocysteine and instead enhance the condensation of this substance with serine into cystathionine. In fact, the $\mathrm{C} \beta \mathrm{S}$ enzyme and the cystathionine content were increased significantly. It is known that several factors are involved in the regulation of $C \beta S$. Exposure of H4IIE cells to triamcinolone, a synthetic corticosteroid, resulted in an increase in C $\beta S$ mRNA and protein expression [11]. It has been suggested that the structural similarity of silymarin to steroid hormones may account for the protein regulating action of these flavonoids [12]. Further studies need to be conducted to determine whether silymarin can affect the $C \beta S$ expression through the steroid-like action.

CDO and GCS are the rate-limiting enzymes involved in the metabolic conversion of cysteine to taurine and GSH, respectively, and therefore the relative ascendancy between the two enzymes determines the metabolic fate of cysteine in the transsulfuration pathway. CDO catalyzes the oxidation of cysteine to cysteinesulfinic acid, which is further metabolized to hypotaurine by the activity of CDC. It has been demonstrated that cysteine itself is an important intracellular signal for upregulation of CDO [13]. A high level of cysteine allows more cysteine to be metabolically converted to cysteinesulfinic acid via induction of CDO. In contrast, GCS is upregulated when cysteine availability is low, ensuring that more cysteine is conserved as GSH [14]. In the present study, silymarin administration inhibited CDO activity and its protein expression despite the elevation of the cysteine level, which may in turn contribute to the accumulation of this sulfur amino acid in liver. This is in line with the results of a recent study demonstrating an increased intracellular cysteine level in predifferentiated 3 T3-L1 cells, which have little CDO enzymes [15]. Therefore, not only the increased cysteine generation from homocysteine via cystathionine, but the reduced cysteine catabolism to taurine would lead to the increment in hepatic cysteine content. The inhibition of CDO did not result in a decrease in hypotaurine and taurine levels in this study. Considering the role of taurine as a major organic osmolyte, it is suggested that the necessity for maintenance of cellular homeostasis may inhibit a rapid change in the intracellular taurine concentration. In fact, a recent study revealed that hepatic CDO-knockout mice fed a taurine-free diet were able to maintain a normal taurine level in liver [16]. The mechanism involved in the inhibition of CDO by silymarin is not known. An earlier study showed that CDO activity was decreased by glucagon treatment via an induction of cAMP [17]. Meanwhile, the anticholestatic effect of silybin was suggested to be associated with an increase in cytosolic cAMP in isolated rat hepatocytes [18]. This raises the possibility that silymarin may affect CDO expression by regulating the cAMP content in liver. Additional studies are needed to clarify the underlying mechanism by which silymarin inhibits the activity and expression of CDO.

Cysteine availability is critical in GSH synthesis, because the hepatic cysteine level is much lower than that of glutamate or glycine. GCS catalyzes the ATP-dependent condensation of cysteine and glutamate to form $\gamma$-glutamylcysteine. Therefore, cysteine availability and GCS activity are the two most important factors determining the generation of GSH. Silymarin treatment did not influence GCS expression or its activity, but elevated the cysteine level in liver significantly, which appeared to account for the increase in hepatic GSH generation. Several flavonoids were suggested to have positive effects on GSH synthesis. Quercetin was shown to induce both GCS activity and the GSH level in HepG2 cells [19]. Also, kaempferol and apigenin increased intracellular GSH by inducing GCS mRNA expression [20]. However, the present results indicate that silymarin may augment the generation of GSH in liver via an increase in cysteine availability without influencing GCS activity or its expression, which subsequently contributes to the enhancement of antioxidant capacity of liver tissues. This is consistent with the reduction of lipid peroxidation and the elevation of TOSC in the liver of the mice treated with silymarin.

In conclusion, the present results show that acute silymarin treatment increases the hepatic GSH level via an enhancement of cysteine availability in naïve mice. To our knowledge, this is the first study revealing that silymarin may induce intracellular GSH content via its direct effects on the metabolism of sulfur amino acids in liver. It is suggested that the elevation of hepatic GSH is associated with the increase in antioxidant capacity of liver in animals treated with this substance. The pharmacological significance of this finding is being evaluated in this laboratory.

\section{Materials and Methods}

$\nabla$

\section{Animals and treatments}

Male C57BL/6 mice, weighing 25-30 g, were purchased from Orient-Bio. The use of these animals was in compliance with the guidelines established by the Animal Care Committee in College of Pharmacy, Seoul National University, and approved by the Ethical Animal Care and Use Committee of Seoul National University (No. SNU-070531-1, 17/07/2007). The mice were acclimated to temperature $\left(22 \pm 2{ }^{\circ} \mathrm{C}\right)$ and humidity $(55 \pm 5 \%)$ controlled rooms with a 12-h light/dark cycle for $1 \mathrm{wk}$ before use. Mice were gavaged with silymarin ( $100 \mathrm{mg} / \mathrm{kg}$ or $200 \mathrm{mg} / \mathrm{kg}$ ) every $12 \mathrm{~h}$ for a total of 3 doses. Silymarin was a kind gift from Bukwang Pharmaceuticals. This product contained silybin (40.9\%) out of the total silymarin ( $81.6 \%$ ) as determined by HPLC with $277 \mathrm{~nm}$ detection. Silymarin was dissolved in a solvent composed of $10 \%$ propylene glycol, $12 \%$ Tween-80, and $78 \%$ distilled water. Control mice received the vehicle only. At $6 \mathrm{~h}$ after the last dosing, the mice were sacrificed for collection of blood and liver samples.

\section{Determination of sulfur-containing amino acids}

The liver was homogenized in $1 \mathrm{M} \mathrm{HClO}_{4}$ for detection of SAM, homocysteine, cysteine, and GSH, or in methanol for detection of methionine, cystathionine, hypotaurine, and taurine. GSH and GSSG were determined using the method of Griffith [21]. For measurement of total GSH, a mixture of NADPH, 5,5'-dithiobis(2-nitrobenzoic acid) and liver sample was preincubated at $35^{\circ} \mathrm{C}$ followed by the addition of GSH reductase. The change in absorbance at $412 \mathrm{~nm}$ was monitored using a UV/VIS spectrophotometer (V-530; Jasco Co.). GSSG was determined using the same procedure after masking GSH with 2-vinylpyridine. Cysteine was determined by the acid-ninhydrin method [22]. An incubation mixture consisting of acid-ninhydrin solution, acetic ac$\mathrm{id}$, and liver sample was incubated at $100^{\circ} \mathrm{C}$ for $10 \mathrm{~min}$. After 
cooling, 95\% ethanol (v/v) was added followed by the absorbance measurement at $560 \mathrm{~nm}$. Methionine, cystathionine, taurine, hypotaurine, and cysteinesulfinic acid were derivatized with $\mathrm{O}$ phthaldialdehyde/2-mercaptoethanol prior to quantification using the method of Rajendra [23]. An HPLC system installed with a $3.5-\mu \mathrm{m}$ Kromasil C18 column $(4.6 \times 100 \mathrm{~mm}$; Eka Chemicals), dual pumps (PU-980; Jasco Co.), and a fluorescence detector (FP920; Jasco Co.) was used. Solvent A (0.1 M sodium acetic acid, $\mathrm{pH} 7.2$ ) and solvent B [methanol: tetrahydrofuran $=97: 3(\mathrm{v} / \mathrm{v})$ ] were used as mobile phases. The flow rate was set at $1.0 \mathrm{~mL} / \mathrm{min}$ and the gradient of solvent $A$ was at 0 min $90 \%, 4-12 \min 84 \%$, $18-22 \min 78 \%, 26-30 \min 70 \%, 47-51 \min 53 \%, 56 \min 30 \%$, 58-62 min 0\%, and $63 \mathrm{~min} 90 \%$. Peaks were detected at excitation and emission wavelengths of $338 \mathrm{~nm}$ and $425 \mathrm{~nm}$, respectively. The method of She et al. [24] was employed to quantify SAM and SAH. A liver sample was injected into an HPLC system with a 3.5- $\mu \mathrm{m}$ Kromasil C18 column ( $4.6 \times 250$ mm; Eka Chemicals). The mobile phase used was $40 \mathrm{mM}$ ammonium phosphate, $8 \mathrm{mM} 1$ heptane sulfonate, and $18 \%(\mathrm{v} / \mathrm{v})$ methanol. The flow maintained at $1.0 \mathrm{~mL} / \mathrm{min}$ was analyzed by a UV detector (UV-975; Jasco Co.). Homocysteine was determined using the method of Nolin et al. [25] with slight modifications. Oxidized and protein-binding forms of homocysteine in liver homogenate were reduced by $5 \mathrm{mM}$ dithiothreitol and an equal volume of $1 \mathrm{M} \mathrm{HClO}_{4}$ was added. After centrifugation, the supernatant was mixed with $1.55 \mathrm{M} \mathrm{NaOH}$. The reaction mixture was incubated with $167 \mathrm{mg} /$ L 7-fluorobenzofurazan-4-sulfonic acid at $60^{\circ} \mathrm{C}$ for $1 \mathrm{~h}$. An HPLC system with a $3.5-\mu \mathrm{m}$ Symmetry C18 column $(4.6 \times 150 \mathrm{~mm}$; Waters), dual pumps, and a fluorescence detector was used to analyze the effluent. Mobile phases were $0.1 \mathrm{M}$ sodium acetic acid (solvent A; pH 4.0) and methanol (solvent B). With a flow rate of $0.8 \mathrm{~mL} / \mathrm{min}$, the gradient of solvent $A$ was at $0-7 \mathrm{~min} 100 \%, 8-$ $13 \mathrm{~min} 25 \%$, and $14.5 \mathrm{~min} 100 \%$. The peak of homocysteine was detected at excitation and emission wavelengths of $385 \mathrm{~nm}$ and $515 \mathrm{~nm}$, respectively.

\section{Enzyme assays}

The liver was homogenized in $0.154 \mathrm{M} \mathrm{KCl} / 50 \mathrm{mM}$ Tris- $\mathrm{HCl}$ and $1 \mathrm{mM}$ EDTA (pH 7.4). The $104000 \mathrm{~g}$ supernatant fraction (cytosol) was used to determine the enzyme activity and protein expression. MAT activity was estimated by quantifying the SAM production. Reaction mixtures consisted of $80 \mathrm{mM}$ Tris- $\mathrm{HCl} / 50 \mathrm{mM}$ $\mathrm{KCl}$ (pH 7.4), $5 \mathrm{mM}$ ATP, $40 \mathrm{mM} \mathrm{MgCl}$, $50 \mathrm{mM}$ methionine, and $1.5 \mathrm{mg}$ protein of cytosol in $1 \mathrm{~mL}$. Incubation was carried at $37^{\circ} \mathrm{C}$ for $30 \mathrm{~min}$. BHMT activity was determined by the method of Ericson and Harper [26]. Cytosol containing $0.167 \%$ betaine and $0.167 \%$ homocysteine was incubated at $37^{\circ} \mathrm{C}$ for $60 \mathrm{~min}$. The reaction was terminated by cold methanol. After centrifugation, the supernatant was analyzed for methionine using the method described above. C $\beta S$ activity was quantified by the cystathionine production [27]. The reaction was carried in a mixture composed of $0.1 \mathrm{M}$ Tris buffer ( $\mathrm{pH} 8.3$ ), $0.1 \mathrm{M}$ serine, $0.12 \mathrm{mM}$ pyridoxal phosphate, $0.5 \mathrm{mM} \mathrm{CuSO}_{4}, 0.1 \mathrm{M}$ homocysteine, and $2 \mathrm{mg}$ protein of cytosol at $37^{\circ} \mathrm{C}$ for $45 \mathrm{~min}$. After centrifugation, the supernatant was incubated in $40 \mathrm{mM}$ acid ninhydrin reagent at $100^{\circ} \mathrm{C}$ for $5 \mathrm{~min}$. The absorbance was detected at $455 \mathrm{~nm}$ using a UV/ VIS spectrophotometer. C $\gamma$ L activity was estimated by the $\alpha$-ketobutyrate formation [28]. Cytosol was incubated in $0.1 \mathrm{M}$ phosphate buffer (pH7.5), $0.05 \mathrm{mM}$ pyridoxal phosphate, $7.5 \mathrm{mM}$ mercaptoethanol, $7 \mathrm{mM}$ EDTA, and $32 \mathrm{mM}$ homoserine for $30 \mathrm{~min}$. After centrifugation, the supernatant was mixed with 0.1\% 2,4-dinitrophenyl hydrazine followed by the addition of ethanol and $2.5 \mathrm{M} \mathrm{NaOH}$. The absorbance was measured at $515 \mathrm{~nm}$ by a UV/VIS spectrophotometer. CDO activity was measured by quantification of cysteine sulfinic acid using the method described above. Cytosol was incubated in $0.5 \mathrm{mM} \mathrm{Fe}$ $\left(\mathrm{NH}_{4}\right)_{2}\left(\mathrm{SO}_{4}\right)_{2}, 5 \mathrm{mM} \mathrm{NH} \mathrm{H}_{2} \mathrm{OH} \cdot \mathrm{HCl}, 2 \mathrm{mM} \mathrm{NAD}$, and $5 \mathrm{mM}$ cysteine for $16 \mathrm{~min}$ at $37^{\circ} \mathrm{C}$. CDC activity was estimated by measuring the hypotaurine production as described above. Cytosol was incubated with $0.1 \mathrm{M}$ phosphate buffer ( $\mathrm{pH} 7.4$ ) containing $0.1 \mathrm{mM}$ pyridoxal 5-phosphate, $2.5 \mathrm{mM}$ dithiothreitol, and $10 \mathrm{mM}$ cysteinesulfinic acid at $37^{\circ} \mathrm{C}$ for $30 \mathrm{~min}$. GCS activity was estimated by the $\gamma$-glutamylcysteine formation. Reaction mixtures contained $0.1 \mathrm{M}$ Tris buffer (pH 8.2), $10 \mathrm{mM}$ L-glutamate, $10 \mathrm{mM}$ ATP, $20 \mathrm{mM} \mathrm{MgCl}_{2}, 2 \mathrm{mM}$ EDTA, $5 \mathrm{mM}$ cysteine, and cytosol. Incubation was continued for $15 \mathrm{~min}$ at $37^{\circ} \mathrm{C}$. $\gamma$-Glutamylcysteine was determined after $O$-phthalaldehyde derivatization using HPLC with a fluorescence detector and a 3.5- $\mu \mathrm{m}$ Symmetry C18 column ( $4.6 \times 75 \mathrm{~mm}$; Waters). The mobile phase consisted of $16 \%$ methanol and $0.21 \%$ acetic acid. The flow rate was set at $1.5 \mathrm{~mL} /$ min. Fluorescence was detected at excitation and emission wavelengths of $360 \mathrm{~nm}$ and $470 \mathrm{~nm}$, respectively.

For Western blotting analysis, $20 \mu \mathrm{g}$ protein of each sample was loaded, separated by gel electrophoresis, and transferred to nitrocellulose membranes by electroblotting. The membranes were blocked in 5\% nonfat dry milk in $0.1 \%$ Tween 20 in Tris-buffered saline. The blots were incubated overnight with primary antibodies in $5 \%$ bovine serum albumin followed by incubation with secondary antibodies. Polyclonal antibodies against rat MAT I/III, $\mathrm{C} \beta \mathrm{S}$, glyceraldehydes-3-phosphate dehydrogenase (Santa Cruz Biotechnology), GCS (NeoMarkers), BHMT, MS (Everest Biotech), CDC (Abcam plc), and CDO were used as probes. The CDO antibody was a kind gift from Dr. Yu Hosokawa (Faculty of Human Sciences, Jissen Women's University, Tokyo, Japan). Proteins were detected by enhanced chemiluminescence.

\section{Measurement of lipid peroxidation and TOSC}

Hepatic lipid peroxidation was quantified by measuring TBARS [29]. The liver was homogenized in $0.154 \mathrm{M} \mathrm{KCl}$. After centrifugation, the supernatant was incubated in a mixture containing trichloroacetic acid (10\%), 2-thiobarbituric acid (0.025\%), and $\mathrm{HCl}$ $(167 \mathrm{mM})$ at $90^{\circ} \mathrm{C}$ for $20 \mathrm{~min}$. After centrifugation at $10000 \mathrm{~g}$, the absorbance was measured at $535 \mathrm{~nm}$ using a UV/VIS spectrophotometer. The method of Regoli and Winston [30] was employed to determine the TOSC of liver cytosolic fraction. This assay is based on the ethylene-yielding reaction of KMBA with peroxyl, hydroxyl radicals, and peroxynitrite. For the TOSC against the peroxyl radical, cytosol was incubated in $1 \mathrm{~mL}$ of a mixture

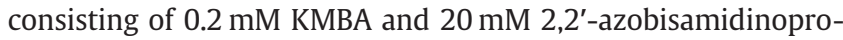
pane in $200 \mathrm{mM}$ potassium phosphate buffer ( $\mathrm{pH} 7.4$ ) at $37^{\circ} \mathrm{C}$ using a sealed 20 -mL glass bottle. For estimation of TOSC against the hydroxyl radical or peroxynitrite, ABAP was substituted for $0.3 \mathrm{mM}$ ascorbic acid, $6 \mu \mathrm{M}$ EDTA, and $3 \mu \mathrm{M}$ ferrous ammonium sulfate or $0.1 \mathrm{mM}$ diethylene triamine pentaacetic acid and $70 \mu \mathrm{M} 3$-morpholinosydnonimine $\mathrm{N}$-ethylcarbamide, respectively. During incubation, an aliquot of upper air in the bottle was taken at intervals and injected into GC (Model 3300; Varian) equipped with a flame ionization detector and porapack $\mathrm{N}$ column (Sigma-Aldrich) for measurement of ethylene. TOSC values were quantified from the equation TOSC $=100-\left(\int S A / \int C A \times 100\right)$, where $\int S A$ and $\int C A$ were the integrated ethylene peak areas obtained from the sample and control reactions, respectively. The specific TOSC was obtained by dividing the experimental TOSC by the weight of the cytosolic protein used. 
Data analysis

All results expressed as the mean \pm SEM were analyzed by a oneway ANOVA followed by the Newman-Keuls multiple range test. The acceptable level of significance was established at $\mathrm{p}<0.05$.

\section{Acknowledgements}

This work was supported by National Research Foundation (NRF) grants (No.2011-0016781 and No.2009-0083533) funded by the Ministry of Education, Science and Technology (MEST), Korea.

\section{Conflict of Interest}

$\nabla$

The authors declare that they have no financial or nonfinancial competing interests.

\section{References}

1 Song Z, Deaciuc I, Song M, Lee DY, Liu Y, Ji X, McClain C. Silymarin protects against acute ethanol-induced hepatotoxicity in mice. Alcohol Clin Exp Res 2006; 30: 407-413

2 Pradeep K, Mohan CV, Gobianand K, Karthikeyan S. Silymarin modulates the oxidant-antioxidant imbalance during diethylnitrosamine induced oxidative stress in rats. Eur J Pharmacol 2007; 560: 110-116

3 Lettéron P, Labbe G, Degott C, Berson A, Fromenty B, Delaforge M, Larrey $D$, Pessayre $D$. Mechanism for the protective effects of silymarin against carbon tetrachloride-induced lipid peroxidation and hepatotoxicity in mice. Evidence that silymarin acts both as an inhibitor of metabolic activation and as a chain-breaking antioxidant. Biochem Pharmacol 1990; 39: 2027-2034

4 Bindoli A, Cavallini L, Siliprandi N. Inhibitory action of silymarin of lipid peroxide formation in rat liver mitochondria and microsomes. Biochem Pharmacol 1977; 26: 2405-2409

5 Varga Z, Seres I, Nagy E, Ujhelyi L, Balla G, Balla J, Antus S. Structure prerequisite for antioxidant activity of silybin in different biochemical systems in vitro. Phytomedicine 2006; 13: 85-93

6 Dehmlow C, Murawski N, de Groot $H$. Scavenging of reactive oxygen species and inhibition of arachidonic acid metabolism by silibinin in human cells. Life Sci 1996; 58: 1591-1600

7 Comoglio A, Tomasi A, Malandrino S, Poli G, Albano E. Scavenging effect of silipide, a new silybin-phospholipid complex, on ethanol-derived free radicals. Biochem Pharmacol 1995; 50: 1313-1316

8 Valenzuela A, Lagos C, Schmidt K, Videla LA. Silymarin protection against hepatic lipid peroxidation induced by acute ethanol intoxication in the rat. Biochem Pharmacol 1985; 34: 2209-2212

9 Valenzuela A, Aspillaga M, Vial S, Guerra R. Selectivity of silymarin on the increase of the glutathione content in different tissues of the rat. Planta Med 1989; 55: 420-422

10 Kim SJ, Lee JW, Jung YS, Kwon DY, Park HK, Ryu CS, Kim SK, Oh GT, Kim YC. Ethanol-induced liver injury and changes in sulfur amino acid metabolomics in glutathione peroxidase and catalase double knockout mice. J Hepatol 2009; 50: 1184-1191

11 Ratnam S, Maclean KN, Jacobs RL, Brosnan ME, Kraus JP, Brosnan JT. Hormonal regulation of cystathionine beta-synthase expression in liver. J Biol Chem 2002; 277: 42 912-42 918

12 Pradhan SC, Girish C. Hepatoprotective herbal drug, silymarin from experimental pharmacology to clinical medicine. Indian J Med Res 2006; 124: 491-504
13 Stipanuk MH, Hirschberger LL, Londono MP, Cresenzi CL, Yu AF. The ubiquitin-proteasome system is responsible for cysteine-responsive regulation of cysteine dioxygenase concentration in liver. Am J Physiol Endocrinol Metab 2004; 286: E439-E448

14 Kwon YH, Stipanuk MH. Cysteine regulates expression of cysteine dioxygenase and gamma-glutamylcysteine synthetase in cultured rat hepatocytes. Am J Physiol Endocrinol Metab 2001; 280: E804-E815

15 Ueki I, Stipanuk MH. 3 T3-L1 adipocytes and rat adipose tissue have a high capacity for taurine synthesis by the cysteine dioxygenase/cysteinesulfinate decarboxylase and cysteamine dioxygenase pathways. J Nutr 2009; 139: 207-214

16 Ueki I, Roman HB, Hirschberger LL, Junior C, Stipanuk MH. Extrahepatic tissues compensate for loss of hepatic taurine synthesis in mice with liver-specific knockout of cysteine dioxygenase. Am J Physiol Endocrinol Metab 2012; 302: E1292-E1299

17 Hosokawa Y, Yamaguchi K, Kohashi N, Kori Y, Ueda I. Decrease of rat liver cysteine dioxygenase (cysteine oxidase) activity mediated by glucagon. J Biochem 1978; 84: 419-424

18 Crocenzi FA, Basiglio CL, Pérez LM, Portesio MS, Pozzi EJ, Roma MG. Silibinin prevents cholestasis-associated retrieval of the bile salt export pump, Bsep, in isolated rat hepatocyte couplets: possible involvement of cAMP. Biochem Pharmacol 2005; 69: 1113-1120

19 Scharf G, Prustomersky S, Knasmuller S, Schulte-Hermann R, Huber WW. Enhancement of glutathione and $\gamma$-glutamylcysteine synthetase, the rate limiting enzyme of glutathione synthesis, by chemoprotective plant-derived food and beverage components in the human hepatoma cell line HepG2. Nutr Cancer 2003; 45: 74-83

20 Myhrstad MC, Carlsen H, Nordström O, Blomhoff R, Moskaug JØ. Flavonoids increase the intracellular glutathione level by transactivation of the gamma-glutamylcysteine synthetase catalytical subunit promoter. Free Radic Biol Med 2002; 32: 386-393

21 Griffith OW. Determination of glutathione and glutathione disulfide using glutathione reductase and 2-vinylpyridine. Anal Biochem 1980; 106: 207-212

22 Gaitonde MK. A spectrophotometric method for the direct determination of cysteine in the presence of other naturally occurring amino acids. Biochem J 1976; 104: 627-633

23 Rajendra $W$. High performance liquid chromatographic determination of amino acids in biological samples by precolumn derivatization with O-phthaldehyde. J Liq Chromatogr 1987; 10: 941-955

24 She QB, Nagao I, Hayakawa T, Tsuge H. A simple HPLC method for the determination of S-adenosylmethionine and S-adenosylhomocysteine in rat tissues: the effect of vitamin B6 deficiency on these concentrations in rat liver. Biochem Biophys Res Commun 1994; 205: 1748-1754

25 Nolin TD, McMenamin ME, Himmelfarb J. Simultaneous determination of total homocysteine, cysteine, cysteinylglycine, and glutathione in human plasma by high-performance liquid chromatography: application to studies of oxidative stress. J Chromatogr B Analyt Technol Biomed Life Sci 2007; 852: 554-561

26 Ericson LE, Harper AE. Effect of diet on the betaine-homocysteine transmethylase activity of rat liver. I. Amino acids and protein. J Biol Chem 1956: $219: 49-58$

27 Kashiwamata S, Greenberg DM. Studies on cystathionine synthase of rat liver. Properties of the highly purified enzyme. Biochim Biophys Acta $1970 ; 212: 488-500$

28 Matsuo Y, Greenberg DM. A crystalline enzyme that cleaves homoserine and cystathionine. I. Isolation procedure and some physicochemical properties. J Biol Chem 1958; 230: 545-560

29 Germanò MP, De Pasquale R, D’Angelo V, Catania S, Silvari V, Costa C. Evaluation of extracts and isolated fraction from Capparis spinosa $\mathrm{L}$. buds as an antioxidant source. J Agric Food Chem 2002; 50: 1168-1171

30 Regoli F, Winston GW. Quantification of total oxidant scavenging capacity of antioxidants for peroxynitrite, peroxyl radicals, and hydroxyl radicals. Toxicol Appl Pharmacol 1999; 156: 96-105 